\title{
Vibration evaluation from the effects of whole-body vibration
}

\author{
M. Uchikune \\ Department of Precision Machinery Engineering, \\ College of Science \& Technology, Nihon University, Japan
}

\begin{abstract}
The purpose of this study is to make clear the physiological and psychological effects on the human body from vibration, and it aims to be a cautionary guide for the application of frequency-weighting curves with respect to health effects.

The standard is not well defined for the difference between the two effects of the human responses.

The study covers short-term exposure and assesses the risks resulting from whole-body vibrations.

For recumbent persons, tests were carried out to find the effect of whole-body vibration in a low frequency range. Physiological effects were examined by investigating the effects on the cardiovascular system, the blood flow system, the respiratory movement, and the salivation, to confirm the effects on the autonomic nervous system and on postural sways in the normal Romberg position.

Keywords: whole-body vibrations, autonomic nervous system, physiological and psychological effects.
\end{abstract}

\section{Introduction}

The aim of this study is to produce a guide for the physiological and psychological measurement of the human body with the vibration where the direction has vertical (z-axis) and horizontal (y-axis) uses.

The standard was shown by the psychological evaluation in relation to the frequency-weighting curves. The health effects of vibration did not show clear responses. 
The guide for the application of frequency-weighting curves for principal weightings are not well defined between the mutual effects.

Concerning the exposure during the short term and the duration of exposure, risks are caused as a result of the recumbent whole-body vibrations.

The vibration dose values at which various degrees of adverse comment may be expected in buildings were based on International Standard 2631-1 [2].

The effects of vibration in buildings for workers are based on the psychological evaluation. The workers must receive the risk of exposure to whole-body vibration, and subjects are measured for the physiological effects for that purpose. In the workplace, there are several possible adverse comments, so the values of the acceleration are shown with on the Critical working areas in the acceleration of $0.2 \mathrm{~m} / \mathrm{s}^{2}$, Residential in $0.4-0.8 \mathrm{~m} / \mathrm{s}^{2}$, Office in $0.8 \mathrm{~m} / \mathrm{s}^{2}$, and Workshops in $1.6 \mathrm{~m} / \mathrm{s}^{2}$. In the traffic system, the public bus (large-sized car, small-sized car) was measured on acceleration from 0.18 to $0.60 \mathrm{~m} / \mathrm{s}^{2}$ and the crane and the container of dock were measured from 0.21 to $0.60 \mathrm{~m} / \mathrm{s}^{2}$ with operators.

The dose values in the above acceleration are applicable irrespective of age, sex, and moreover, the whole-body vibration occurs as a continuous vibration.

It was necessary that the composition of the Standard for whole-body vibration including the health effects of vibration on the autonomic nervous system were studied in this paper.

\section{Method}

This study was performed using multi-input vibration testing equipment in the large structure testing building at this faculty. The university students were used as the subjects of an age group (average age; 22.5 years old), all in good health, and male.

The subjects lay down in the recumbent position on the vibration table and covered their ears with earmuffs. This vibrating condition was examined from $0.04,0.06,0.1,0.2$, and 0.4 to $0.8 \mathrm{~Hz}$ with the horizontal and the vertical recumbent whole-body vibration. Such a vibration frequency can be an everyday occurrence in a workshop and may result in an occupational disease. The amplitudes of vibration table were $25,50,100,125$ and $150 \mathrm{~mm}$ in that it the accelerations of vibration ranged over $0.0067(150 \mathrm{~mm}-0.04 \mathrm{~Hz}), 0.0100$ $(100 \mathrm{~mm}-0.06 \mathrm{~Hz}), \quad 0.0279 \quad(100 \mathrm{~mm}-0.1 \mathrm{~Hz}), \quad 0.140 \quad(125 \mathrm{~mm}-0.2 \mathrm{~Hz}), \quad 0.223$ $(50 \mathrm{~mm}-0.4 \mathrm{~Hz})$ and $0.447(25 \mathrm{~mm}-0.8 \mathrm{~Hz}) \mathrm{m} / \mathrm{s}^{2}$.

These accelerations were examined the range, including the low probability of an adverse comment in Standard.

The examination used the sinusoidal wave for z-axis (vertical) and y-axis (lateral) for a period of 15-min. Waveforms were produced by this multi-input vibration testing equipment.

Physiological effects were examined by the changes on the cardiovascular system, respiratory movement, skin temperature, blood flow, and salivation. As in our previous experiment of seated subjects, physiological changes were found, and this state acted on the sympathetic and the para-sympathetic nervous 
system. Table 1 shows the state of the function on the autonomic nervous system.

The physiological indicators are shown the opposite action of the physiological responses on human body for exposure to vibration.

Table 1: $\quad$ Opposite action of autonomic nervous system.

\begin{tabular}{|l|c|c|}
\hline \multicolumn{1}{|c|}{ Physiological indicator } & state of sympathetic & para-sympathetic \\
\hline Function of heart & Increase & Restraint \\
\hline Function of respiration & Increase & Restraint \\
\hline Function of skin temperature & Restraint & Increase \\
\hline
\end{tabular}

It is necessary to know the threshold level, the direction, and the exposure time in the work place. The sensors of measurement used were the thermistor, bio-amp., blood flow meter, thermometer, balance test meter, and $\mathrm{pH}$ meter and the outputs were replaced from the amp to be recorded onto a recorder.

The amount of the saliva secretion was measured at intervals of 3-minutes by inserting a dental cotton roll under the tongue. The heart-rate ratio and respiratory frequency were expressed as a ratio of each measured value to the reference values of the said elements with 30 seconds as a criterion value prior to vibrating (baseline value) as a criterion value. As for the measuring time in the cases of heart-rate ratio and respiratory frequency, a series of measurements were performed for 30 seconds at intervals of 3-minutes.

An introspective method used was one in which the feelings aroused in a subject's mind were described as one of the suitable items in an evaluation paper after the experiment. In accordance with a semantic differential method (SD method), the terms of adequate for the low frequencies were chosen with respect to the 7-grade evaluation.

The evaluation points were given as shown below. Psychological evaluation by the introspective method of numerical values showed that six (item of comfortable) and seven grades were converted to scale numbered 7 in which, "4" represented "normal". These grades were selected according to the twenty-one items. The words were as follows: adaptable, unpretentious, amusing, smooth, friendly, calm, sharp, active, violent, favorite, variable, fresh, strong, heavy, hard, security, speedy, aggressive, tired, unpleasant, and great.

These words were based on our previous study and it found the suitable word for this vibration among them. It used VAS (visual analog scale) method at a time. The subjects marked the line of $100 \mathrm{~mm}$ with a pencil freely what the subjects felt the vibration.

\section{Results and conclusions}

The opposite action of the autonomic nervous system functioned to keep the human body constant, so the function of heart rate and respiratory rate increased on the state of sympathetic nervous system and was restrained on the para- 
sympathetic nervous system. The decreasing of the salivation is caused by sympathetic nervous system and the increasing is caused by the state of parasympathetic nervous system.

That shows the effects of the acceleration and the frequency of the head, which are to be transmitted to the human body. The physiological indicator showed the ratio as follows and the each measured value divided by the before exposure to vibration was shown the ratio.

Table 2: An example of the physiological responses to vibration over $15 \mathrm{~min}$.

\begin{tabular}{|l|l|l|}
\hline $\begin{array}{l}\text { Physiological } \\
\text { indicator }\end{array}$ & z-axis: $0.447 \mathrm{~m} / \mathrm{s}^{2}$ & y-axis: $0.447 \mathrm{~m} / \mathrm{s}^{2}$ \\
\hline Heart-rate & $1.01,0.06$ & $1.01,0.06$ \\
Movement & $2.50,1.65$ & $1.30,0.62$ \\
Respiratory & $1.17,0.15(\mathrm{p}<0.10)$ & $1.24,0.21(\mathrm{p}<.10)$ \\
Saliva & $0.46,0.27(\mathrm{p}<0.01)$ & $0.60,0.38$ \\
pH & $0.92,0.06(\mathrm{p}<0.05)$ & $0.98,0.07$ \\
Blood flow & $1.17,0.48$ & $1.16,0.22$ \\
Skin temp. & $0.997,0.025$ & $0.994,0.015$ \\
& & \\
\hline
\end{tabular}

Ratio after stimulation / before stimulation (exposure to vibration). P: probability, (mean, SD).

The table gives analytical results brought about from the observation referred to above.

Table 2 shows the state of the sympathetic nervous system with sinusoidal wave for $\mathrm{z}, \mathrm{y}$-axes (vertical, horizontal direction) and the acceleration of the recumbent posture was at $0.447 \mathrm{~m} / \mathrm{s}^{2}$ r.m.s. These results calculated the heart rate, the movement of baseline, the respiratory rate, the saliva secretion, the $\mathrm{pH}$ of saliva, the blood flow of index finger and the skin temperature of middle finger during 15-min (male aged 21-26). On the sinusoidal wave for z-axis (vertical direction), the skin temperature decreased the acceleration of 0.223 and $0.447 \mathrm{~m} / \mathrm{s}^{2}$ r.m.s. at $15-\mathrm{min}$. The increase was noted in the physiological indicator by the heart-rate ratio, the respiratory rate ratio and movement of baseline with heart at $0.8 \mathrm{~Hz}-25 \mathrm{~mm}\left(0.447 \mathrm{~m} / \mathrm{s}^{2}\right)$, during 15 -min, whereas decreased in the amount of the saliva secretion and $\mathrm{pH}$ in these data and the results compared these data with the baseline value. The blood flow of the index finger decreased in comparison with control and $0.0067 \mathrm{~m} / \mathrm{s}^{2}$ values.

At the y-axis (lateral direction) in Table 2, it was shown that the physiological effects changed the frequent occurrence during 15 -min at $0.447 \mathrm{~m} / \mathrm{s}^{2}$ r.m.s.

The increase was noted in the physiological indicator by the heart-rate ratio, the movement of baseline, the respiratory rate at $0.8 \mathrm{~Hz}-25 \mathrm{~mm}\left(0.447 \mathrm{~m} / \mathrm{s}^{2}\right)$, 
during 15-min, whereas decreases in the amount of the saliva secretion, the blood flow of index finger and the skin temperature of middle finger during $15-\mathrm{min}$ at $0.8 \mathrm{~Hz}-25 \mathrm{~mm}\left(0.447 \mathrm{~m} / \mathrm{s}^{2}\right)$, whereas decreases in the amount of the saliva secretion in these data and the results compared these data with the baseline and with control and $0.0067 \mathrm{~m} / \mathrm{s}^{2}$ values.

The decrease of the $\mathrm{pH}$ ratio was noted in the vibration frequency at $0.223 \mathrm{~m} / \mathrm{s}^{2}-50 \mathrm{~mm}-0.4 \mathrm{~Hz}, 0.447 \mathrm{~m} / \mathrm{s}^{2}-25 \mathrm{~mm}-0.8$ during $15-\mathrm{min}$ and the decrease of $2.0 \%$ band was caused in these ranges, compared these data with the baseline value, whereas in $0.0067 \mathrm{~m} / \mathrm{s}^{2}-150 \mathrm{~mm}-0.04 \mathrm{~Hz}$, and $0.0279 \mathrm{~m} / \mathrm{s}^{2}-100$ $\mathrm{mm}-0.1 \mathrm{~Hz}$ were increased $1.0-2.4 \%$ values.

For the recumbent persons, it considered the experimental values, and the guide for the application of frequency-weighting curves was shown for health weightings.

It was implicated that the state of value in this range was due to the transmissibility caused by the vibration frequency.

The length and the area of body sway were registered with closed eyes and opened eyes by using the balance meter, then the subjects stood on the balance meter with both feet.

It showed the ratios of the area of body sway when the subjects' eyes were closed and opened (c/o; ratio of measurements with closed eyes to measurements with opened eyes) and it tended to increase with amplitudes of $25,50 \mathrm{~mm}$, frequency of $0.4,0.8 \mathrm{~Hz}$, and acceleration at $0.223,0.447 \mathrm{~m} / \mathrm{s}^{2}$.

The effects of these accelerations were shown in the movement-area of body sway when the eyes were closed and opened, then Romberg ratio as shown from 1.6 to 1.8 .

Psychological evaluation by the introspective method of numerical values showed that six and seven grades were converted to scale numbered $(1-6,7)$ in which "4" represented "normal". It was believed that when the acceleration was "unpleasant" to exceed $0.223 \mathrm{~m} / \mathrm{s}^{2}$. On the subjects, $0.223 \mathrm{~m} / \mathrm{s}^{2}$ or $0.447 \mathrm{~m} / \mathrm{s}^{2}$ decreased to 4.3, 2.8 (SD method; y-axis, level: 1-7) and 4.0, 3.2 (SD method; zaxis, level: 1-7) of the evaluation value and that low frequency area which gave "normal for pleasant" in the range $0.0067,0.010,0.0279$, and $0.140 \mathrm{~m} / \mathrm{s}^{2}$. Those data were shown at frequency range from 0.04 to $0.2 \mathrm{~Hz}$. The uncomfortable tended to increase with increasing of acceleration to exposure vibration for lateral and vertical axes (y-and z-axes).

The assessment of the discomfort was shown a scale of vibration magnitudes (level: 1-6) and $0.223 \mathrm{~m} / \mathrm{s}^{2}$ or $0.447 \mathrm{~m} / \mathrm{s}^{2}$ decreased to 4.1 (y-axis) and 4.7 (z-axis).

In the VAS method with regard to unpleasant was noted for evaluation word and the evaluation point exhibited below 40 (scale: 100 ) at $0.447 \mathrm{~m} / \mathrm{s}^{2}$, then the tendency was shown the same data for $y$-and z-axes.

The same adjective of physiological tendency was "hard, great, strong, violent, active, sharp, aggressive, and speedy". The difference of the evaluation point, at which the axes were not the same values, showed contribution to the effects of acceleration for the recumbent posture.

The correlation was shown as examples in the Table 3. 
There is a close relationship between the acceleration and the frequency for VAS and SD methods.

Table 3: The correlation of the psychological level.

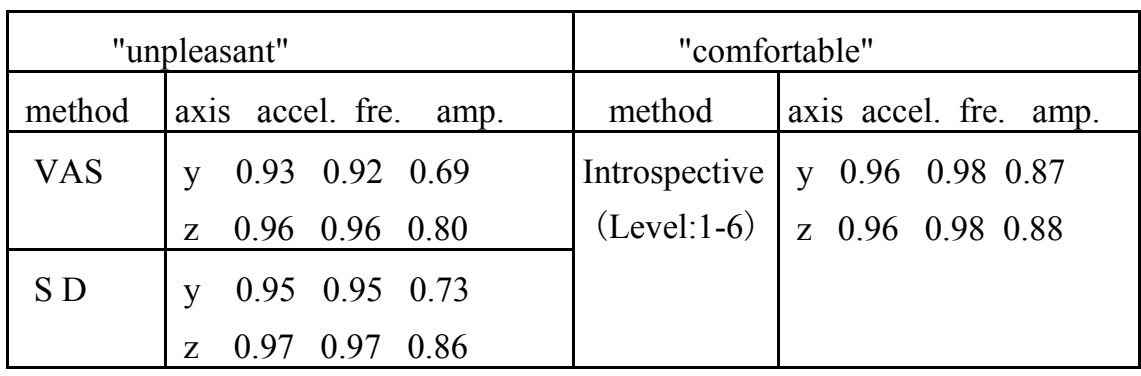

The state of predominance of the sympathetic nervous system was shown at $0.447 \mathrm{~m} / \mathrm{s}^{2}$ in $15-\mathrm{min}$ (z: vertical, y: lateral).

Furthermore, it showed the range of the effects of vibration on health in the directions of the $z, y$-axes to the human body under the environments of this vibration zone.

According to a report concerning the experiment, it was found that the health effects found in acceleration ranging from $0.223 \mathrm{~m} / \mathrm{s}^{2}$ in horizontal and vertical directions of the frequency ranging from $0.4 \mathrm{~Hz}$, were seen when transmitted to a human body; where it was desirable to widen a frequency weighting curves.

The magnitude of whole-body vibration for health aspects may consider the weighting as the vibration frequency for recumbent posture.

The assessment must be made that the risk resulting from this experiment of whole-body vibrations are affected to the physiological and psychological level.

\section{References}

[1] Dupuis H., Zerlett G., Responses of whole-body vibration. Translation: Matsumoto T., Okada A., Ariizumi M., Nohara S., \& Inaba R., Nagoya Univ.-Press, Japan, pp. 62-109, 1989.

[2] International Organization for Standardization, ISO2631 Part 1, 1997.

[3] Nakamura Y., Psychological and Social Psychology. Kosei-Press Co., Japan, 1976.

[4] Oshima M., Theory of Vibration on Human Body. Tokyo Univ.- Press, Japan, 1969.

[5] Uchikune M., Yoshida Y., Studies of the effects of low frequency vibration on the human body -Physiological and psychological effects of low frequency horizontal vibration-. Proc. of the 11th Int. Conf. On the Ergonomics Association. IEA, Paris, pp. 915-917, 1991.

[6] Uchikune M., Yoshida Y., \& Shirakawa S., Studies on the effects of low frequency horizontal vibration to the human body. Low fre. noise, vibra. \& active control, (13), pp. 139-142, 1994. 
[7] Uchikune M., Shirakawa S., \& Yoshida Y., The effects of a low frequency range exposed to vibration on the whole-body. Proc. of the 25th Int. Conf. On occupational health. ICOH, Stockholm, p. 222, 1996.

[8] Uchikune M., Shirakawa S., \& Yoshida Y., Studies in physiological effect and psychological evaluation on a human body with the low frequency vibration. Proc. of the 13th Int. Conf. On the Ergonomics Association. IEA, Tampere, pp. 602-604, 1997.

[9] Uchikune M., Yoshida Y., The effects on exposure of the whole-body to low frequency vibration in the range $0.01-0.06 \mathrm{~Hz}$. Low fre. noise, vibra. \& active control, (18), pp. 77-83, 1999.

[10] Uchikune M., Shirakawa S., Studies for the evaluation of human-body exposure to whole-body vibration at very low frequencies. Proc. of the 14th Int. Conf. On the Ergonomics Association. IEA, San Diego, p. 58, 2000 .

[11] Uchikune M., Health effects of feet vibration on autonomic nervous system. Proc. of the 26th Int. Conf. On Occupational Health. ICOH, Singapore, p.705, 2000.

[12] Uchikune M., Development of a vibration acceleration meter for low frequency range. The Japanese society of tech. education.(42), pp.75-81, 2000.

[13] Uchikune M., The evaluation of horizontal whole-body vibration in the low frequency range. Low fre. noise, vibra. \& active control, (21), pp. 2936, 2002.

[14] Uchikune M., Effects on health and perception from whole-body vibration exposure. Proc. of the third Int. Conf. On Women, Work \& Health, Stockholm, pp. 89-90, 2002.

[15] Yoshida Y. (eds.), Fundamental of Human Ergonomics. Corona-Press Co., Japan, 1980.

[16] Uchikune M., Measurement and evaluation of whole-body vibrations. Proc. of the second Int. Conf. RISK 2003, Catania, pp. 143-149, 2003.

[17] Gurmail S Paddan, Measurement, analysis and assessment of whole-body vibration according to ISO2631-1:1997. Proc. of the 11th JGHRV2003 Meeting, Japan, pp. 174-183, 2003.

[18] Uchikune M., Measurement of whole-body vibration strain for the standing posture. Proc. of the 11th Int. Meeting, Maastricht, pp. 359-365, 2004. 